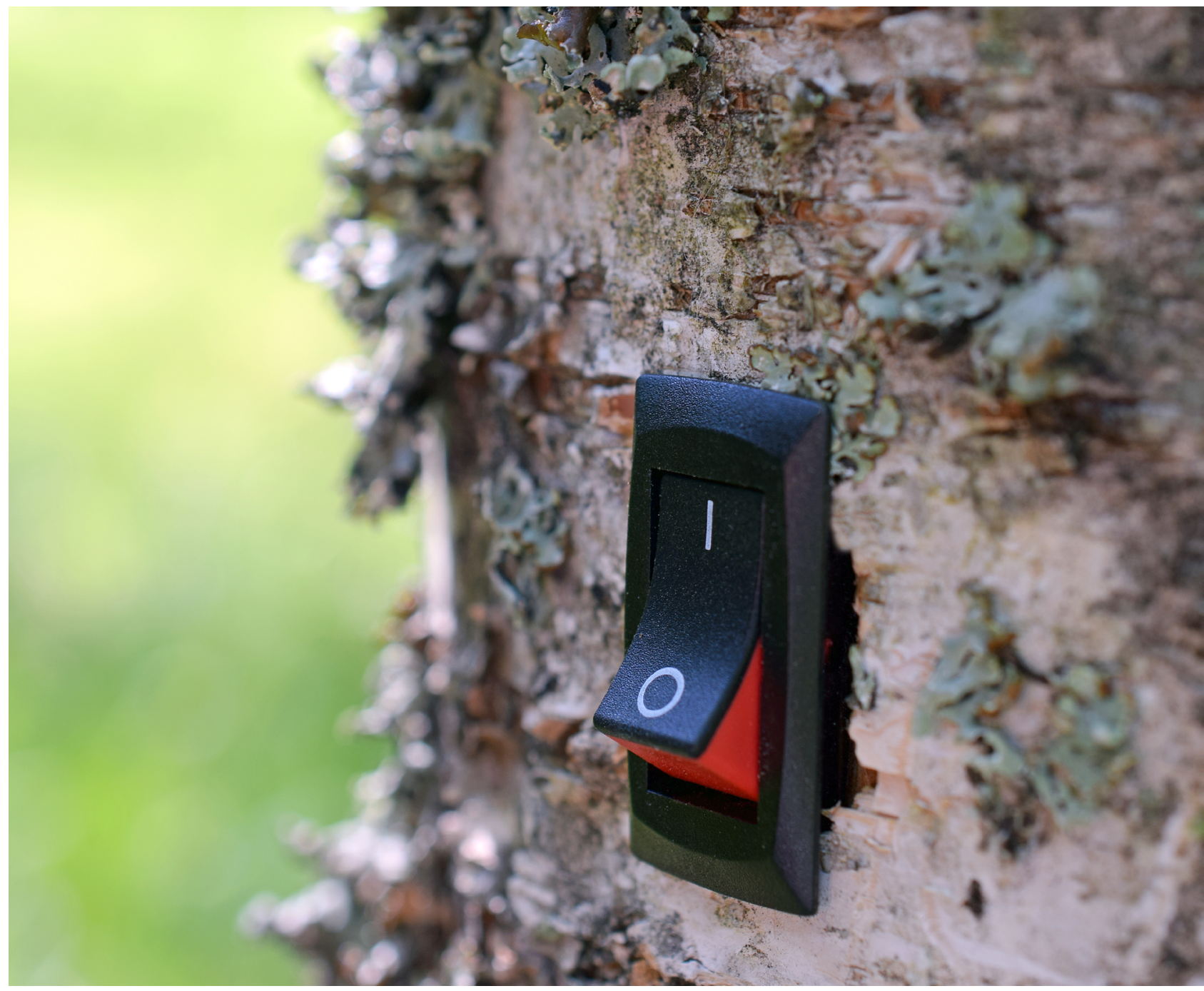

\title{
POR QUE É TÃO DIFÍCIL MONTAR UM NEGÓCIO CONVINCENTE
}

EMPREENDEDORES DE STARTUPS DE TECNOLOGIA LIMPA MOSTRAM QUE RARAMENTE SAEM BOAS PROPOSTAS DE VALOR SÓ DE POST-ITS E CANVAS. É PRECISO IR AO MERCADO, TESTAR FORMAS DE OFERECER O PRODUTO OU SERVIÇO E ENGAJAR CLIENTES EM UM PROCESSO COLABORATIVO DE COCRIAÇÃO. 


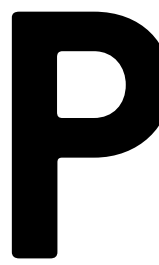

reocupações com o consumo consciente não são um luxo para empresas de países desenvolvidos. Pesquisa conduzida pelo Serviço Brasileiro de Apoio às Micro e Pequenas Empresas (Sebrae) aponta que, no Brasil, 91\% dos empreendedores acreditam que a sustentabilidade gera oportunidades de novos negócios e $67 \%$ dizem adotar práticas sustentáveis na empresa. A realidade pós-pandemia torna o tema ainda mais relevante. Segundo pesquisa da McKinsey \& Company com consumidores brasileiros, novos valores vêm emergindo durante a crise da Covid-19, especialmente a consciência ao consumir e a visão de planeta e sociedade em primeiro lugar.

Nota-se, assim, o desenvolvimento de um mercado vibrante no Brasil, centrado na inovação para melhoria do desempenho ambiental, englobando tecnologias para eficiência energética, energia renovável, otimização do aproveitamento de água, transporte verde, entre outros direcionamentos. A esse conjunto de negócios dá-se o nome de cleantechs (veja no quadro). Por exemplo, a Sun Mobi, empresa de que o autor deste artigo é sócio, permite que clientes tenham acesso à energia solar via um modelo por assinatura e sem necessidade de comprar equipamentos, assim como a Stattus 4 desenvolveu um sistema baseado em inteligência artificial e internet das coisas para monitorar perdas na distribuição de água, e a Vela Bikes criou modelos nacionais de bicicletas elétricas.

\section{A RELEVÂNCIA DA PROPOSTA DE VALOR}

A inovação tecnológica em benefício do meio ambiente, no entanto, não garante automaticamente o sucesso comercial ou econômico das cleantechs. Assim como qualquer outro empreendimento, uma vez identificada a oportunidade, é fundamental que o empreendedor se debruce sobre o desenho de um modelo de negócio que permita sua monetização.

Apesar dos inúmeros artigos científicos, livros e tutoriais online disponíveis sobre modelos de negócio, ainda não há um guia definitivo sobre o tema, mas existe um consenso entre acadêmicos e executivos de que no âmago do modelo de negócio está a proposta de valor. O termo proposta de valor é creditado aos consultores Michael Lanning e Edward Michaels, que o definiram como "uma declaração clara e simples dos benefícios, tangíveis e intangíveis, que a empresa fornecerá, juntamente com o preço aproximado

\section{ÁREAS EM QUE ATUAM AS CLEANTECHS}

\begin{tabular}{|c|c|c|c|}
\hline Energia limpa & Armazenamento de energia & Eficiência & Transporte \\
\hline $\begin{array}{l}\text { - Eólica } \\
\text { - Solar } \\
\text { - Combustíveis renováveis } \\
\text { - Energia dos oceanos } \\
\text { - Biomassa } \\
\text { - Geotérmico } \\
\text { - Células de } \\
\text { combustível } \\
\text { - Resíduos } \\
\text { (WTE - waste of energy) } \\
\text { - Nuclear } \\
\text { - Hídrica }\end{array}$ & $\begin{array}{l}\text { - Sistema de armazenamento } \\
\text { químico } \\
\text { - Sistema de armazenamento } \\
\text { técnico } \\
\text { - Sistema de armazenamento } \\
\text { mecânico } \\
\text { - Sistema de armazenamento } \\
\text { elétrico }\end{array}$ & $\begin{array}{l}\text { - Redes inteligentes (smart grid) } \\
\text { - Arquitetura verde (green building) } \\
\text { - Cogeração } \\
\text { - Semicondutores } \\
\text { - Sistemas de consumo } \\
\text { colaborativo }\end{array}$ & $\begin{array}{l}\text { - Veículos } \\
\text { - Gestão de tráfego } \\
\text { - Infrestrutura de abastecimento/ } \\
\text { carregamento }\end{array}$ \\
\hline Ar e meio ambiente & Indústria limpa & Água & Agricultura \\
\hline $\begin{array}{l}\text { - Sequestro de carbono } \\
\text { - Mercado de carbono } \\
\text { - Controle de emissões } \\
\text { - Biorremediação } \\
\text { - Reaproveitamento } \\
\text { de resíduos } \\
\text { - Monitoramento } \\
\text { e conformidade }\end{array}$ & $\begin{array}{l}\text { - Inovação em materiais } \\
\text { - Inovação em design } \\
\text { - Inovação em equipamentos } \\
\text { - Processos produtivos } \\
\text { - Monitoramento } \\
\text { e conformidade } \\
\text { - Embalagem } \\
\text { ecológica }\end{array}$ & $\begin{array}{l}\text { - Produção } \\
\text { - Tratamento } \\
\text { - Distribuição } \\
\text { - Eficiência no uso da água } \\
\text { - Monitoramento e conformidade }\end{array}$ & $\begin{array}{l}\text { - Cultivo } \\
\text { - Agricultura em ambiente } \\
\text { controlado } \\
\text { - Silvicultura sustentável } \\
\text { - Criação de animais } \\
\text { - Aquicultura }\end{array}$ \\
\hline
\end{tabular}

FONTE: MAPEAMENTO DO ECOSSISTEMA DE STARTUPS DE CLEANTECH NO BRASIL, 2019 


\section{MENSAGENS DO TIPO COMPRE ESTE PRODUTO SUSTENTÁVEL E ECONOMIZE LEVAM À REDUÇÃO DO DESEJO DE COMPRA, POIS CONSUMIDORES SUSTENTÁVEIS DUVIDAM DA SERIEDADE DO NEGÓCIO E CONSUMIDORES SENSÍVEIS AOS APELOS ECONÔMICOS SENTEM QUE PODERIAM GANHAR MAIS SE ABRISSEM MÃO DAS QUESTOÕES ECOLÓGICAS.}

que cobrará". Parece trivial, entretanto a maioria dos negócios não tem propostas de valor claramente articuladas. Pesquisa feita por Adrian Payne, da Universidade de Nova Gales do Sul, e Pennie Frow, da Universidade de Sydney, com mais de 200 empresas indicou que, embora muitas empresas usem o termo em suas discussões diárias, menos de $10 \%$ desenvolvem, comunicam e usam formalmente propostas de valor.

Um conjunto de estudos tem demonstrado que o tema é ainda mais relevante no contexto das cleantechs. Seu público-alvo é sensível aos benefícios socioambientais da tecnologia comercializada e, dessa forma, a falta de clareza da proposta de valor, com mistura de elementos ambientais e elementos econômicos, pode levar à redução no interesse de clientes e investidores. Por exemplo, de acordo com estudo realizado por Laura Marie Edinger-Schons e Jenni Sipilä, da Universidade de Mannheim, Sankar Sen, do Baruch College, e Gina Mende e Jan Wieseke, da Universidade de Bochum, mensagens do tipo compre este produto sustentável e economize levam à diminuição do desejo de compra, pois consumidores sensíveis aos apelos ambientais duvidam dos compromissos da empresa com a sustentabilidade e consumidores sensíveis aos apelos econômicos sentem que poderiam ganhar um pouco mais se abrissem mão das questões ecológicas.

Vale também destacar um experimento com investidores de venture capital conduzido por Moritz Loock, do Instituto para Economia e Meio Ambiente da Universidade de St. Gallen. Esse estudo identificou que gestores de investimentos em energia renovável priorizam aportes em modelos de negócio que propõem melhores tecnologias ou melhores serviços aos clientes e que esses mesmos investidores se sentem desencorajados a injetar recursos em modelos de negócio baseados em ofertas de preços mais baixos.

\section{INSIGHTS SOBRE A REALIDADE BRASILEIRA}

No Brasil, mapeamento recente do ecossistema de cleantechs realizado pela Escola de Administração de Empresas de São Paulo, da Fundação Getulio Vargas (FGV EAESP), em conjunto com EDP, Instituto Alberto Luiz Coimbra de Pós-Graduação e Pesquisa de Engenharia, da Universidade Federal do Rio de Janeiro (Coppe/UFRJ), Associação Brasileira de Startups (Abstartups) e Agência Nacional de Energia Elétrica (Aneel), concluiu que um dos principais desafios enfrentados por essas startups é conseguir comunicar de forma persuasiva suas propostas de valor. Diante dessa dificuldade, estamos conduzindo um estudo que envolve entrevistas com empreendedores proprietários de startups de cleantech no Brasil para entender o processo de construção das propostas de valor. Os primeiros insights do trabalho indicam que o desenvolvimento das propostas de valor que resultam em sucesso no acesso ao mercado passa por três aspectos principais:

- Interatividade do processo: A introdução de um produto ou serviço ligado a tecnologias limpas apresenta o desafio inicial de se descobrir, simultaneamente, o perfil ideal dos clientes-alvo e os atributos de valor com maior atratividade para esse mercado. Na experiência dos empreendedores entrevistados, esta etapa requereu muitas idas e vindas, em um processo de experimentação e aprendizado que, no jargão dos empreendedores, são as chamadas pivotagens. Talvez um dos casos mais emblemáticos de pivotagem no universo do empreendedorismo seja o do Twitter, que passou de uma plataforma de podcasts para se tornar uma das redes sociais mais valiosas do planeta;

- Cocriação: Os empreendedores entrevistados mencionaram a importância da proximidade com clientes potenciais e efetivos desde a fase inicial de pivotagens até o momento em que seus modelos de negócio já estavam tomando forma mais definitiva. Na visão deles, a maneira de aprimorar a proposta de valor que funcionou foi por meio de um processo de cocriação com seus clientes, muitas vezes mediante a elaboração de pilotos. A Sun Mobi, por exemplo, trabalhou com cocriação em um aplicativo para o monitoramento do consumo de energia para permitir a seus clientes identificar oportunidades de eliminação de desperdícios, levando-os a adotar práticas sustentáveis de consumo em complemento ao uso de energia limpa; 


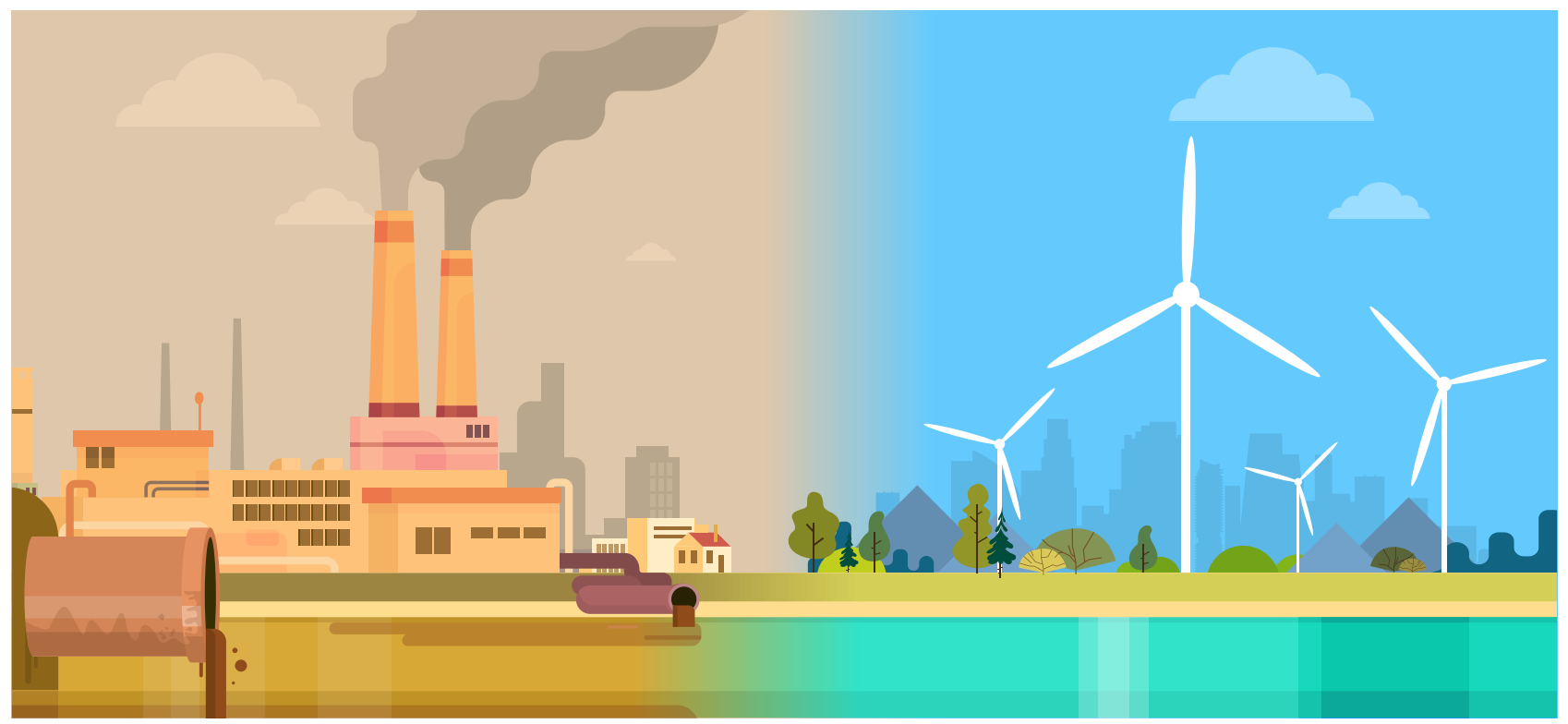

\section{A MELHOR MANEIRA DE APRIMORAR A PROPOSTA DE VALOR É PELA CRIAÇÃO CONJUNTA DE PILOTOS COM CLIENTES, EM UM PROCESSO DE EXPERIMENTAÇÃO E DE MELHORIA CONTÍNUA.}

- Melhoria contínua: A famosa frase utilizada pelos bancos nos seus prospectos de investimento, rentabilidade passada não garante sucesso futuro, também se aplica aqui. Os empreendedores mencionaram a necessidade de manter viva a roda de aprendizado e cocriação para garantir aprimoramento da proposta de valor. No escopo da melhoria contínua, incluem-se não só questões associadas diretamente à tecnologia, mas também quanto à forma de relacionamento com os clientes e demais elementos do modelo de negócio. O episódio recente do pedido de recuperação judicial da Grow, startup de destaque no mercado de micromobilidade urbana que atuava com aluguel de bicicletas e patinetes elétricos, pode ser considerado como uma boa ilustração desse ponto. Apesar de todo o buzz ao redor do negócio e do uso do serviço por consumidores de alta renda, especialmente na cidade de São Paulo, a empresa não pareceu ter sido capaz de ajustar seu modelo de negócio, incluindo a proposta de valor para todos os seus stakeholders, o que a deixou em condições frágeis já antes do início da pandemia.

\section{MÃOS À OBRA E PÉ NA RUA}

O principal desafio dos empreendedores de cleantechs é desenvolver um modelo de negócio que permita a monetização de tecnologias limpas por meio de uma proposta de valor consistente, com menos recursos que seus concorrentes diretos e indiretos já estabelecidos.
Nesse contexto, a primeira lição essencial da nossa pesquisa é que o desenho da proposta de valor não é um produto elaborado pelo empreendedor apenas na fase de planejamento do negócio, com ou sem a ajuda de consultores, sentado em uma sala de reuniões, usando post-its e canvas. Trata-se de um processo contínuo, longo e trabalhoso que envolve sair a mercado, testar formas distintas de ofertar o produto ou serviço e, idealmente, engajar os clientes em um processo colaborativo de cocriação. Assim como andar de bicicleta, mesmo depois de definida a proposta de valor e encontrado um modelo de negócio mais estável, deve-se continuar pedalando, ouvindo os clientes e cocriando com eles, para se manter firme no mercado.

\footnotetext{
PARA SABER MAIS:

- Adrian Payne e Pennie Frow. Developing superior value propositions: a strategic marketing imperative. Journal of Service Management, v.25, n.2, 2014. Disponivel em: doi.org/10.1108/JOSM-01-2014-0036

Laura Marie Edinger-Schons, Jenni Sipilä, Sankar Sen, Gina Mende e Jan Wieseke. Are two reasons better than one? The role of appeal type in consumer responses to sustainable products. Journal of Consumer Psychology, v.28, n.4, 2018. Disponivel em: doi.org/10.1002/ jcpy.1032

EDP, COPPE/UFRJ, FGV EAESP, Abstartups e Aneel. Mapeamento do ecossistema de startups de cleantech no Brasil: relatório parcial, 2019. Disponivel em: bitly/gvexeccleantech

Moritz Loock. Going beyond best technology and lowest price: on renewable energy investors' preference for service-driven business models. Energy Policy, v.40, 2012 Disponivel em: doi.org/10.1016/j.enpol.2010.06.059

Serviço Brasileiro de Apoio às Micro e Pequenas Empresas (Sebrae). Engajamento dos pequenos negócios brasileiros em sustentabilidade e aos objetivos do desenvolvimento sustentável (ODS), 2018
}

GUILHERME SUSTERAS > Doutorando do Doctorate in Business Administration (DBA) da FGV EAESP > susteras@gmail.com 